\title{
Social Stereotypes in Communicative Formulae: Sociometric Approach
}

\author{
Natalya Zavyalova ${ }^{1}$ \\ ${ }^{1}$ Ural Federal University (UrFU), Ekaterinburg, Russian Federation \\ Correspondence: Natalya Zavyalova, Ural Federal University (UrFU), 620002, 19 Mira street, Ekaterinburg, \\ Russian Federation.
}

Received: May 26, 2014 Accepted: June 18, 2014 Online Published: July 29, 2014

doi:10.5539/ass.v10n15p242 URL: http://dx.doi.org/10.5539/ass.v10n15p242

\begin{abstract}
The focus of the article is centered on society through the prism of communication. Modern data extraction and information retrieval methods allow building a new vision of communicative process. The article is focused on the example of language idiom representations and omnibus survey, which help concentrate on the most stable human society ways of expression. There is also an attempt to carry out a comparative analysis of social features of the East and the West with the help of on-line national languages' corpuses. Omnibus survey results testify to the fact that low income people are reluctant to admit the influence of idioms on their day-to-day communicative practices, while rich people stress the significance of stable communicative formulae in their life. Societies are described through their attitude to labor, expressed in the idioms with a 'hand' component. With the help of electronic linguistic corpuses (Corpus of the Internet and business Chinese), KOTONOHA (Balanced Corpus of Contemporary Written Japanese), BNC (British National Corpus), COCA (Corpus of Contemporary American English) the research analyzes labor stereotypes on the basis of idiom frequency indexes. In practice the results of this study can be implemented in a special socio-cultural dictionary, where the most frequent idioms are given as social stereotypes and the most powerful symbolic tools of influence and manipulation. The results of these findings are relevant to multicultural societies, migration adaptation practices and global business development. The research results have been processed into a database, marked with the Rospatent Certificate (№ 2013620397, dated 03/13/2013. Rightholder: Limited Liability Company 'Content-Press' (RU). First Author: Yakovlev Igor Gennadievich (RU). Second Author: Zavyalova Natalya Alekseevna (RU)).
\end{abstract}

Keywords: society, communication, idiom, data extraction, information retrieval

\section{Introduction}

For more than 6000 years society members have been channeling themselves through communication - from cave paintings to Facebook pages content. As S. Benhabib has masterfully formulated: 'To be and to become a self is to insert oneself into webs of interlocution' (Benhabib, 2002). Sociology uses a number of communicative methods, based on interviewing people (see Lamont \& Swidler, 2014).

The approach is based on the assumption that for sociological purposes it is possible to concentrate on analyzing the language itself, rather than employing it as a useful tool. But the world of language is vast. Which language items are of primary importance for describing social mechanics? The proposed answer is the domain of idioms, as they represent culture connotations, codes and symbols, describing the ideas of 'good' and 'bad' in every society. In his spectacular work Jeffrey C. Alexander specified the road, taken by the notion of Holocaust from the simple idiom of 'atrocities of war' to the Testament idiom 'the dominant evil of our time' (Alexander, 2003).

With the help of Serelex system of semantically related words (Panchenko et al., 2013) a list of semantically related words to the head word 'idiom' was extracted (see Graph 1).

The figure demonstrates that idioms have been a part of society life for centuries, dating back to Gregorian chants and up to such exclamations as: eeee, ooooh and programming idioms in the $21^{\text {st }}$ century.

Though society members are reluctant to admit the fact that they are governed by idiomatic stereotypes, it is possible to insist on the assumption that moral standards, fixed in idioms, are transferred from generation to generation. They perform the function of prior impressions, which affect our present perception: 'in every case the perceptual process is the same: Prior experience colors perception' (Goldstein et al., 2008). The hypothesis is 
that societies neglect the importance of idiomatic stereotypes in their day-to-day life, though they are driven by them.

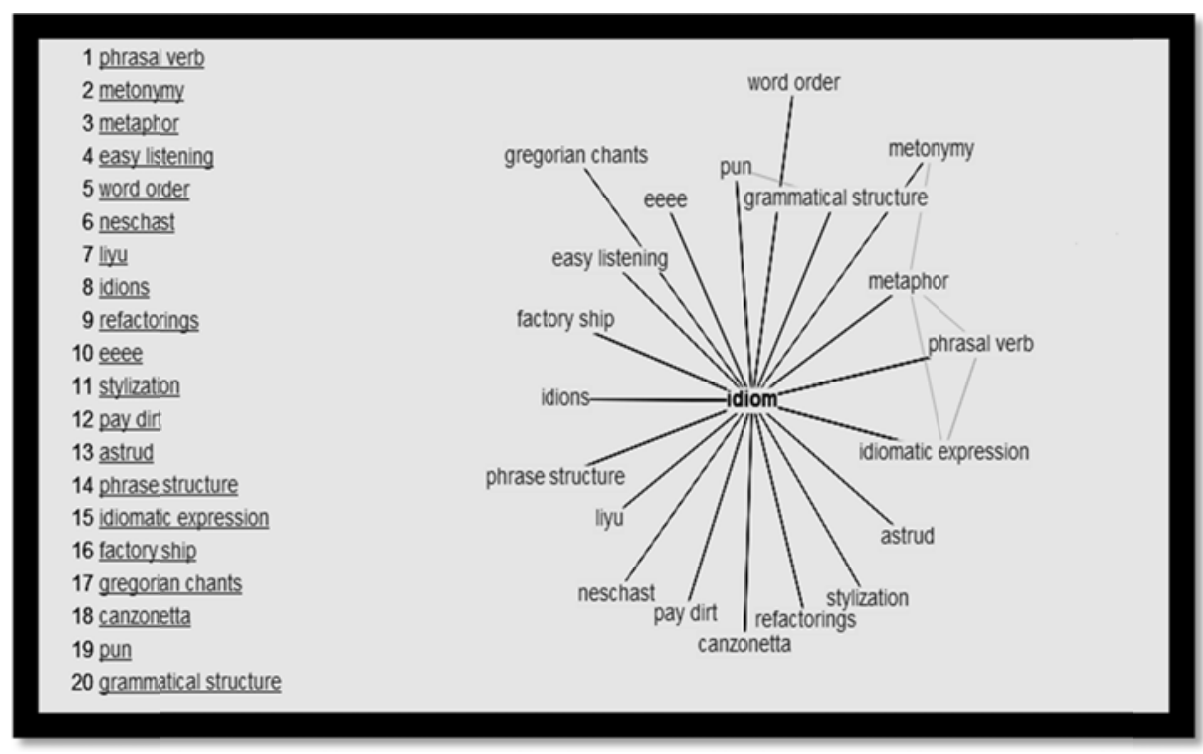

Figure 1. Idiom representation within the web of semantically related words: http://serelex.cental.be/\#idiom (retrieved: 04/21/2014).

The figure demonstrates that idioms have been a part of society life for centuries, dating back to Gregorian chants and up to such exclamations as: eeee, ooooh and programming idioms in the $21^{\text {st }}$ century.

Though society members are reluctant to admit the fact that they are governed by idiomatic stereotypes, it is possible to insist on the assumption that moral standards, fixed in idioms, are transferred from generation to generation. They perform the function of prior impressions, which affect our present perception: 'in every case the perceptual process is the same: Prior experience colors perception' (Goldstein et al., 2008). The hypothesis is that societies neglect the importance of idiomatic stereotypes in their day-to-day life, though they are driven by them.

The second stage of the theory is devoted to societal important analysis of labor related idioms with the 'hand' component through a cross-cultural prism. Representatives of different societies express their ideas according to universal parameters of their body. Thus, it is productive to analyze societies, paying attention to both: points of similarity and differences, expressed in stereotypes with body components. 'Hand' component idioms assist to a better understanding of labor representations in different cultures. This vision is very important for irradiating occupational imbalances (Ankudinov \& Lebedev, 2013).

\section{Data and Methods}

Stage 1. In order to prove the fact that people neglect the influence of idioms in their lives an omnibus survey in cooperation with 'Yuri Levada Analytical Center' was conducted. Levada center carries out nationwide polls in Russian Federation, which are based on a representative sample of 1600 people over 18+ from 130 sampling points across 45 regions of Russian Federation.

The sample did not include the Chechen and Ingush Republics, as well as remote and sparsely populated regions of the Far North (Nenets, Yamal-Nenets, Taimyr Autonomous Region, the Evenki Autonomous District, Kamchatka, Chukotka, Sakhalin Oblast). There were 9 Russian areas, totally excluded from consideration. The adult population in the excluded areas did not exceed $4 \%$. Residents of small settlements with a population of less than 50 people (about $0.8 \%$ of the adult population of Russia), the military (about $0.8 \%$ of the adult population of Russia), the person in custody or detention during the investigation (about $0.8 \%$ of the adult population of Russia), as well as homeless people (up to $1.5 \%$ of the adult population of Russia) were not included to the survey. 
In each federal district independently all the primary sampling units were divided into strata according to their population number:

1. The city of more than 1 million people;

2. The town numbering from 500 thousand to 1 million people;

3. The town numbering from 100 thousand to 500 thousand people;

4. Urban settlements of up to 100 thousand people ;

5. Villages.

These 5 categories were further subdivided into smaller groups. Given the characteristics of population distribution in the regions 36 strata were formed. The total sample (1,600 respondents) was distributed proportionally among all strata of the adult population in each stratum. The number of primary sampling units was determined from the restrictions on the average number of respondents in the same town / rural area (7-13 respondents).

The central survey question was as follows: 'Do you use common routine expressions, quotations from films and public speeches of famous people, bad language set expressions in your day-to-day life'? All these linguistic terms are referred to the domain of idioms in Russian. Parallel to this question Levada center obtained the information about the financial situation of the respondents. Their second question concerned the respondents' affordability to purchase goods.

Stage 2. The next stage of the analysis was devoted to on-line language corpus information extraction. With the help of electronic linguistic corpuses (Corpus of the Internet and business Chinese), KOTONOHA (Balanced Corpus of Contemporary Written Japanese), BNC (British National Corpus), COCA (Corpus of Contemporary American English) body stereotypes were analyzed on the basis of idiom frequency indexes. The 'hand' component is a common part of body idioms and it manifests actions, labor instruments and working agents' relationships.

For the analysis of the ability to act there was decided to describe idioms with a 'hand' component in Chinese, Japanese and English. Most frequent idioms are viewed as the best examples of action strategies, which represent the action 'self' of the nation. Action stereotypes were singled out; they are viewed as a core component of social national standards. Operating with huge masses of information, stored in corpuses, provides a researcher with a reliable ground for making conclusions. The most frequent idioms are the ones, preferred by national society representatives.

\section{Analysis and Results}

Stage 1. Consider the omnibus survey results with the help of table 1 and graph 2 . The results reflect yes/no answers to the question 'Do you use common routine expressions, quotations from films and public speeches of famous people, bad language set expressions in your day-to-day life?' The table also describes the purchasing power of the respondents.

Table 1. Omnibus survey results, obtained in February, 2014 in Russian Federation by Yuri Levada Analytical center.

\begin{tabular}{cccccc}
\hline & Total & only food & food and clothes & expensive utensils & a car \\
\hline Total & $\mathbf{1 6 0 3}$ & 211 & 851 & 467 & 75 \\
1, yes \% & $\mathbf{4 3 , 1}$ & 39,4 & 42,9 & 43,5 & 52,9 \\
$\mathbf{2 , \text { no } \%}$ & $\mathbf{5 6 , 8}$ & $\mathbf{6 0 , 6}$ & 56,8 & 56,5 & 47,1 \\
\hline
\end{tabular}

The survey results demonstrate that the balance of 'yes/no' answers is fairly equal. $43,1 \%$ of respondents admitted the fact that they were using idioms in their day-to-day life, while 56,8 \% answered negatively. Though the number of positive answers is high enough, there was assumed that every second person in Russian Federation refused to admit the importance of idioms in his/her social discourse. The difference is striking in the poorest segment of the survey group, members of which can afford to buy only food. On the contrary, in the richest segment the difference is not rigid. 
Figure 2. Omnibus survey results, obtained in February, 2014 in Russian Federation by Yuri Levada Analytical center.

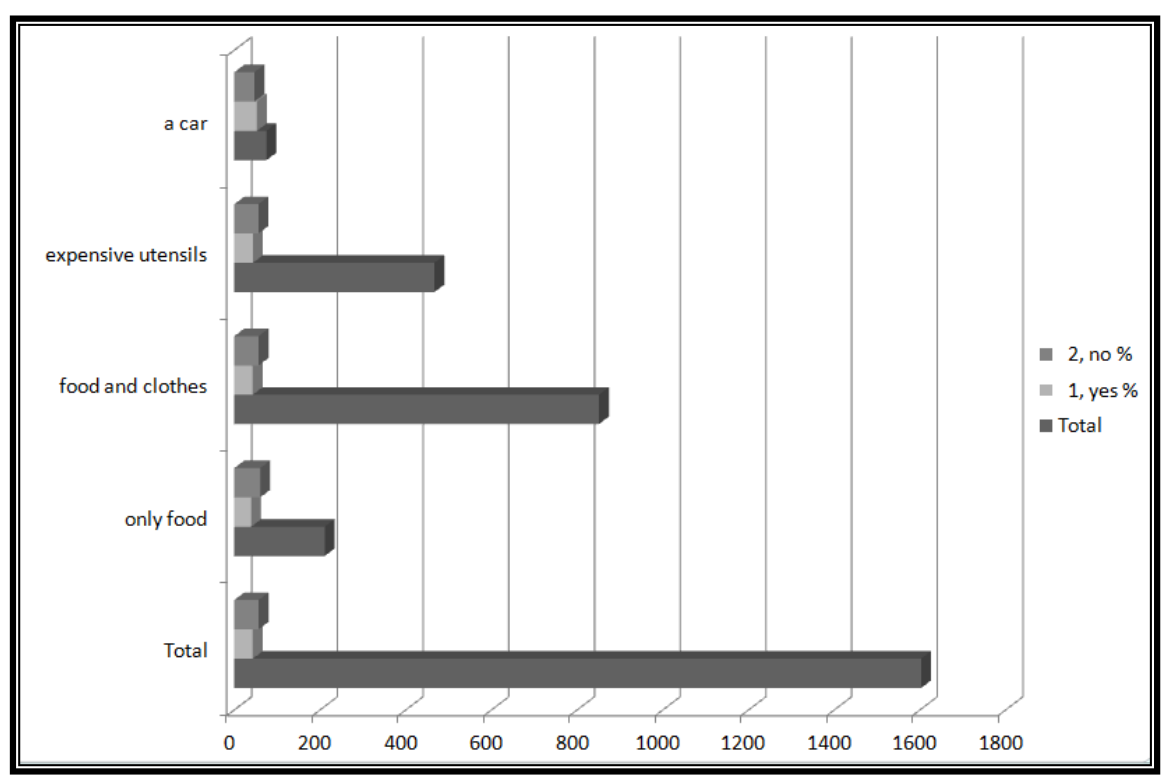

From the first stage of their life people are driven by idioms in the process of socialization. 'While a child might get by in the world without ever using the passive, or even a common lexical item like ball, the child who does not learn to say hi, thanks, and goodbye will become a despised member of society. Anything that can have such an effect cannot be unimportant' (Greif \& Gleanson, 1980).

Stage 2. The subject matter at this stage is cross-cultural corpus analysis of idioms with a 'hand' component.

The stage starts with the analysis of Chinese idioms. For analyzing Chinese idioms' frequencies the research used Chinese corpus of Leeds University. Each idiom was provided with the frequency index, illustrating its usage frequency in the Internet and business Chinese. The results are as follows.

Bái 2 shŏu 3 q $\breve{3}$ jiā 1 - «to build a house with white hands» - build up from nothing, from scratch [the Internet 291; business Chinese - 300]. Dà4 shŏu 3 dà4 jiăo3 - «a big hand, a big foot» - to be extravagant [the Internet 221; business Chinese - 247]. Gü zhăng nán míng - «one hand can’t clap» - hard to achieve by oneself [the Internet - 38; business Chinese - 30].

Chinese idioms with the highest frequencies. $Q \bar{u} z h \breve{l} k \breve{e} s h \breve{u}$ - «can be counted on the fingers» - can be counted on the fingers, very few [the Internet - 427; business Chinese - 373]. Aì4 bù4 shi4 shŏu 3 - «to love, not releasing hands» - to be attached, to love passionately [the Internet - 574; business Chinese - 250].

The analysis shows that hands' skills are marked positively in Chinese society and culture. Both hands are viewed as a source of revenues, achievements and success. On the contrary, one hand is perceived as a disadvantage. Unique skills, which can be counted on fingers, are viewed as a substantial bonus.

Japanese idioms have been analyzed with the help of KOTONOHA on-line corpus of modern written Japanese. It submits the contexts of a considerable time period between 1880 to 2008. Let's discuss the results of the research.

Sen te-o toru - «to take an earlier hand» - to be the first, to go ahead [26 contexts from 1920 to 2008. Male contexts - 16, female contexts - 4]. Tanagokoro-o kaesu yo:-ni - «as if to turn the palms» - effortlessly, very easy, with shut eyes [3 contexts from 1900 to 1940. Male contexts -4 ].

Japanese idioms with the highest frequencies. Oku-no te - «the hand from the mystery» - the last resort [51 contexts from 1890 to 2008. Male contexts - 34, female contexts - 12]. Sen te-o utsu - «to take an earlier hand» - to be the first, to go ahead [73 contexts from 1910 to 2008. Male contexts - 53, female contexts - 14].

According to Japanese standards, expressed in idioms, it is possible to assume that 'hand' is viewed as the source of positive action, resulting in advancement and progress. It is also viewed as a violent threat instrument in fights. It is critical to have an 'an earlier hand', or 'flowers in both hands'. 'The hand from the mystery' is viewed as a secret tool, sophisticated mechanism, operating behind the scenes. 
The researchers used British (BNC) and American (COCA) corpuses to analyze English idioms. The results are as follows.

Hand in hand - [BNC - 274; COCA - 1143 (2012-1990)]. To bind hand - [BNC - 7; COCA - 23 (2012-1990)]. Hand and glove - [BNC - 0; COCA - 6 (2009-1993)]. To catch smb. red-handed - [BNC - 36; COCA - 137 (2012-1990)].

British and American idioms with the highest frequencies.

$A$ helping hand - [BNC - 119; COCA - 372 (2012-1990)]. The upper hand - [BNC - 119; COCA - 707 (2012-1990)]. Out of hand - [BNC - 372; COCA - 1442 (2012-1990)]. At hand - [BNC - 475; COCA - 3341 (2012-1990)].

British and American people value assistance and power. They stress the operational side of a hand and like to have things within a hand's reach.

\section{Discussion}

The research demonstrates that there are various theoretical and practical implications of the analysis. The survey is limited to idioms. Idioms are not simple words; they represent road maps, according to which society is functioning. Though many society members, especially those with low income, refuse to admit the fact that they use such words in their day-to-day life.

As any information system, the system of social communicative signs can be described in terms of mathematical laws. The central idea is that idioms should be analyzed within the framework of information maximum. The principle of information maximum firstly appeared in the works by Shannon (et. al, 1963) and later it was developed by Soviet and Russian scholars (see Golytsin \& Petrov, 2005): 'the system tries to find such response $y$, which enables the maximum of useful information about the given stimuli $x$ '.

$\mathrm{L}(\mathrm{X}, \mathrm{Y})=\mathrm{H}(\mathrm{Y})-\mathrm{H}(\mathrm{Y} / \mathrm{X})-\beta \mathrm{R}(\mathrm{X}, \mathrm{Y}) \rightarrow \max$,

where $H(Y)$ - the entropy of the system's conditions, $H(Y / X)$ - the entropy of the system's mistakes and its reactions to outer stimuli, $\mathrm{R}(\mathrm{X}, \mathrm{Y})$ - the average consumption of the system's resource in $\mathrm{Y}$ condition within all $X$ environmental conditions, and $\beta$ - the indicator of the system's deficit ( $\beta=0$, when the system has an unlimited energy resource, и $\beta=1$ when the system has a very big energy deficit)" (Ibid.).

According to the described above principle, all informational systems develop within 3 main strategies:

\section{THE PRINCIPLE OF INFORMATION MAXIMUM}

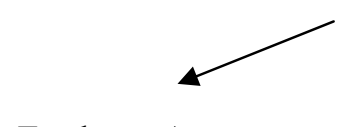

Tendency A

Expansion

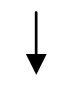

Tendency B

Idealization

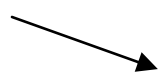

$\underline{\text { Tendency } \mathrm{C}}$

Resource Saving

Expansion is realized through new varieties and numbers of environmental conditions, in which the analyzed system can exist. This tendency is sometimes called 'searching behavior' tendency H (Y). While idealization is concentrated on the tendency to minimize the system's mistakes entropy, idealization is sometimes known as the 'conservative behavior' tendency $\mathrm{H}(\mathrm{Y} / \mathrm{X})$. It is achieved mainly through the repetition of the best variants. Resource saving is realized in 2 possible ways: 1) minimizing the resource spent $R(X, Y) ; 2)$ minimizing the indicator of the system's deficit $B$ by means of resource growth. The research is limited to the analysis of Chinese, Japanese, American, British and American idioms, their strategies of idealization, reflected in the most frequent idioms.

'Hand' component is viewed as something very important in every society under analysis. This results in the idea that there is no critical difference in moral judgment of actions and labor in different cultures. Unique skillful labor is always positively marked and viewed as a substantial benefit. Hand color is of significant importance and differs from culture to culture. While 'red-handed' component in Chinese is synonymous to an open and fair action, it is viewed negatively as an evidence of crime and evil in Anglo-Saxon communicative discourse. The number of fingers is of much relevance, as well. Exclusive phenomena are viewed through the number of fingers in Chinese and Japanese cultures. The position and order of hands is culturally significant. Usually 'upper' and 'earlier' positions are analogues to success and power. 


\section{Summary}

Representatives of different cultures express their ideas according to universal parameters of their body perception. Thus it is more productive to analyze societies, paying attention to points of similarity, rather than concentrating on slight differences, expressed in false stereotypes. 'The basis for all stereotyping is the differential perception of groups. Without such differentiation between groups, stereotyping cannot occur' (Hamilton et al., 1986). J. Wilson stresses that stereotypes ' $\ldots$ have been shown to be remarkably resilient to change' (Wilson, 2006). Despite this fact, it is possible to assume that it is very important to concentrate on the common anthropological basis of humankind, fixed in communicative idioms, which testifies to the fact, that it is hard to draw a sharp line of demarcation among representatives of different societies.

In practice the results of this study can be implemented in a special socio-cultural dictionary (see Zavyalova, 2013), where the most frequent idioms are given as social stereotypes and the most powerful symbolic tools of influence and manipulation. The practical implications of the study lie within the domain of social influence area, driven by communicative idiomatic stereotypes and the problem of meaning in sociology (see Berezin, 2014). The theoretical value of this research is the expansion of idiom status, whose role for the society analysis has been minimized to purely linguistic phenomena. The research proceeds from the idea that idioms are social in nature. Thus, their careful analysis adds to the profound understanding of social life and economic environment, as A. Samuels rightfully put it 'disputes concerning human nature underlie many debates on economic theory' (Samuels, 2014). The results of these findings are relevant to multicultural societies, migration adaptation practices and global business development. Further research should contribute to analysis of expansion and resource saving strategies.

\section{References}

Alexander, J. C. (2003). The Meanings of Social Life: A cultural Sociology (pp. 32-34). Oxford University Press, Inc. http://dx.doi.org/10.1093/acprof:oso/9780195160840.001.0001

Ankudinov, A. B., \& Lebedev, O. V. (2013). Empirical analysis of employees with tertiary education occupational imbalances. American Journal of Applied Sciences, 10(10), 1134-1139. http://dx.doi.org/10.3844/ajassp.2013.1134.1139

Benhabib, S. (2002). The Claims of Culture: Equality and Diversity in the Global Era (p. 15). Princeton University Press.

Berezin, M. (2014). How Do We Know What We Mean? Epistemological Dilemmas in Cultural Sociology. Qualitative Sociology. Springer Science Business Media New York. http://dx.doi.org/10.1007/ s11133-014-9276-x

BNC: British National Corpus. Retrieved March 10, 2014, from http://corpus.byu.edu/bnc

COCA: Corpus of Contemporary American English. Retrieved March 10, 2014, from http://corpus.byu.edu/coca

Corpus of the Internet and business Chinese. Retrieved March 10, 2014, from http://corpus.leeds.ac.uk/ query-zh.html

Goldstein, N. J., Martin, S. J., \& Cialdini, R. B. (2008). Yes!: 50 Scientifically Proven Ways to Be Persuasive (p. 167). A Division of Simon and Schuster, Inc. New York.

Golytsin, G. A., \& Petrov, V. M. (2005). Social and Cultural Dynamics: Long-term Tendencies (Information Approach) (pp. 24-27.). Moscow: KomKniga, (in Russian).

Greif, E. B., \& Gleanson, J. B. (1980). Hi, thanks, and goodbye: More routine information. Language in Society, 9(2), 159-166. http://dx.doi.org/10.1017/S0047404500008034

Hamilton, D. L., \& Troiler, T. K. (1986). Stereotypes and stereotyping: An overview of the cognitive approach. In J. Dovidio, \& S. Gaertner (Eds.), Prejudice, discrimination, and racism (p. 134). Orlando: Academic Press.

KOTONOHA: Balanced Corpus of Contemporary Written Japanese. Retrieved March 10, 2014, from http://www.kotonoha.gr.jp/shonagon/search_form

Lamont, M., \& Swidler, A. (2014). Methodological Pluralism and the Possibilities and Limits of Interviewing. Qualitative Sociology. Springer Science Business Media New York. http://dx.doi.org/10.1007/ s11133-014-9274-z

Panchenko, A.ab , Romanov, P.b , Morozova, O.a, Naets, H.a, Philippovich, A.b, Romanov, A.b, \& Fairon, C.a Lecture notes in computer science (including subseries lecture notes in artificial intelligence and lecture 
notes in bioinformatics). Volume 7814 LNCS, 2013, pp: 837-840. 35th European Conference on Information Retrieval, ECIR 2013; Moscow; Russian Federation; 24 March 2013 through 27 March 2013; Code 96205. http://dx.doi.org/10.1007/978-3-642-36973-5_97

Samuels, A. (2014). Economics, psychotherapy and politics. International Review of Sociology: Revue Internationale de Sociologie. http://dx.doi.org/10.1080/03906701.2014.894348

Shannon, C. E., \& Weaver, W. (1949). The Mathematical Theory of Communication (Urbana III, pp. 20-80). University of Illinois Press.

Wilson, J. (2006). 'Unpacking' the OE: An exploration of New Zealand 'overseas experience' (p. 134). Unpublished PhD thesis. Lincoln University, Lincoln, New Zealand.

Yuri Levada Analytical Center. Retrieved February 10, 2014, from www.levada.ru/eng/

Zavyalova, N. (2013). Socio-cultural acquisition through idiomatic representation. World Applied Sciences Journal, 27(13A), 445-449.

Zavyalova, N. (2013). Idiomatic Frequencies as Indicators of Socio-Cultural Acquisition. World Applied Sciences Journal, 27(13A), 439-444.

\section{Copyrights}

Copyright for this article is retained by the author(s), with first publication rights granted to the journal.

This is an open-access article distributed under the terms and conditions of the Creative Commons Attribution license (http://creativecommons.org/licenses/by/3.0/). 